\title{
Diminished Brain Glucose Metabolism Is a Significant Determinant for Falling Rates of Systemic Glucose Utilization during Sleep in Normal Humans
}

Patrick J. Boyle, James C. Scott, Andrew J. Krentz, Roger J. Nagy, Eileen Comstock, and Charles Hoffman Division of Endocrinology and Metabolism, Department of Medicine, and the Department of Anesthesiology, University of New Mexico, Albuquerque, New Mexico 87131

\begin{abstract}
Systemic glucose utilization declines during sleep in man. We tested the hypothesis that this decline in utilization is largely accounted for by reduced brain glucose metabolism. 10 normal subjects underwent internal jugular and radial artery cannulation to determine cerebral blood flow by $\mathrm{N}_{2} \mathrm{O}$ equilibrium technique and to quantitate cross-brain glucose and oxygen differences before and every $3 \mathrm{~h}$ during sleep. Sleep stage was graded by continuous electroencephalogram, and systemic glucose turnover was estimated by isotope dilution. Brain glucose metabolism fell from 33.6 $\pm 2.2 \mu \mathrm{mol} / 100 \mathrm{~g}$ per min (mean $\pm \mathrm{SE}$ ) before sleep $(2300 \mathrm{~h}$ ) to a mean nadir of $24.3 \pm 1.1 \mu \mathrm{mol} / 100 \mathrm{~g}$ per min at $0300 \mathrm{~h}$ during sleep $(P=0.001)$. Corresponding rates of systemic glucose utilization fell from $13.2 \pm 0.8$ to 11.0 $\pm 0.5 \mu \mathrm{mol} / \mathrm{kg}$ per $\min (P=0.003)$. Diminished brain glucose metabolism was the product of a reduced arteriovenous glucose difference, $0.643 \pm 0.024$ to $0.546 \pm 0.020 \mathrm{mmol} /$ liter $(P$ $=0.002)$, and cerebral blood flow, $50.3 \pm 2.8$ to $44.6 \pm 1.4 \mathrm{cc} /$ $100 \mathrm{~g}$ per $\min (P=0.021)$. Brain oxygen metabolism fell commensurately from $153.4 \pm 11.8$ to $128.0 \pm 8.4 \mu \mathrm{mol} / 100 \mathrm{~g}$ per $\min (P=0.045)$. The observed reduction in brain metabolism occurred independent of stage of central nervous system electrical activity (electroencephalographic data), and was more closely linked to duration of sleep. We conclude that a decline in brain glucose metabolism is a significant determinant of falling rates of systemic glucose utilization during sleep. (J. Clin. Invest. 1994. 93:529-535.) Key words: brain • glucose metabolism • oxygen metabolism • sleep • electroencephalogram
\end{abstract}

\section{Introduction}

Major changes in metabolism occur during sleep. These alterations include such diverse events as decrements in central nervous system electrical activity (1), reduced basal metabolic rate (2), decreased cardiac output (3), as well as concomitant reductions in rates of systemic glucose turnover in normal (4) and diabetic humans (5). In direct response to sleep, adrenocorticotrophin (6), and growth hormone (7) are released from the anterior pituitary and exert major influences on systemic glucose metabolism during the ensuing hours (8-10). Two recent reviews consolidate the fragments of our present knowl-

Address correspondence to Dr. Patrick J. Boyle, University of New Mexico School of Medicine, Department of Medicine/Endo - 5ACC, Albuquerque, NM 87131.

Received for publication 21 December 1992 and in revised form 21 September 1993.

J. Clin. Invest.

(C) The American Society for Clinical Investigation, Inc.

0021-9738/94/02/0529/07 \$2.00

Volume 93, February 1994, 529-535 edge of the metabolism of sleep $(11,12)$, yet substantial details regarding interrelationships between brain and whole body fuel kinetics are incomplete.

Despite the above mentioned well-known physiologic responses during sleep, direct relationships between brain glucose metabolism and falling systemic glucose turnover have never been investigated. Mangold demonstrated stable cerebral blood flow and oxygen consumption in sleep-deprived humans before sleep and immediately after the onset of it (13). Unfortunately, these early studies were not continued though the remainder of the sleep period, and quantification of brain glucose metabolism was not included. Subsequently, a number of investigations have quantitated cerebral blood flow (14-16), oxygen metabolism (17), or glucose metabolism (18-21) immediately before the onset of sleep and generally once more during the night. None of these investigations included serial, simultaneous measurements of whole brain blood flow with oxygen and glucose metabolism to evaluate any direct effect that duration of sleep might have on these parameters. Likewise, no previous investigation has included measurement of systemic glucose turnover to assess potential associations with central nervous system metabolism.

The brain's major fuel is glucose, and during the postabsorptive period, brain glucose metabolism accounts for $>50 \%$ of systemic glucose utilization (22). Because of the major contribution the brain plays in total glucose consumption, it is reasonable to suggest that minor decrements in brain glucose metabolism could account for a substantial part of the fall in systemic glucose metabolism during the night. In this investigation, we demonstrate that whole brain glucose metabolism falls in parallel with systemic glucose metabolism and quantitatively accounts for a significant fraction of the reduction observed during sleep in normal humans.

\section{Methods}

Subjects. 12 normal volunteers ( 7 men and 5 women) gave their informed consent to participate in investigations approved by the $\mathrm{Hu}$ man Research Review Committee at the University of New Mexico. Their ages were between 19 and 39 (mean \pm SE, $25 \pm 2 \mathrm{yr}$ ). All were within $10 \%$ of their ideal body weight. None was taking any medication, and all had normal screening laboratory chemistry studies before being included for participation.

Protocol. On the night before the night of formal investigation, subjects were admitted to the General Clinical Research Center and allowed to sleep from $\sim 2300$ to $0300 \mathrm{~h}$, and were then kept awake for the remainder of the night and the next day. At $1500 \mathrm{~h}$, eight electroencephalogram (EEG) ${ }^{1}$ leads were placed $(\mathrm{C} 3, \mathrm{C} 4, \mathrm{O} 1, \mathrm{O} 2, \mathrm{LOC}, \mathrm{ROC}$ referenced to $\mathrm{M} 1$ and $\mathrm{M} 2$ [international 1020 electrode placement system], as well as a chin muscle channel for electromyography). The evening meal was completed by $1730 \mathrm{~h}$, and the subjects were allowed

1. Abbreviation used in this paper: EEG, electroencephalogram. 
to rest until $1800 \mathrm{~h}$. Under sterile conditions an 18-gauge flexible, 8inch cannula was introduced into the right internal jugular vein and advanced to the level of the internal jugular bulb. Subjects characteristically noted a discomfort in their ear when the cannula reached the jugular bulb, and it was then withdrawn $2 \mathrm{~mm}$. Roentgenogram of the lateral skull confirmed the location of the cannula tip in all participants. Left radial arterial and antecubital intravenous cannulas were introduced for blood sampling and infusions, respectively. $2 \mathrm{~h}$ before beginning blood sampling for glucose kinetics, a primed continuous infusion of $6,6-\mathrm{D}_{2}$-glucose was started to allow estimation of rates of systemic glucose production and utilization.

Measurements of cerebral blood flow were conducted after the technique of Kety and Schmidt (23) and are described in detail below. In general, two measurements were made before sleep and then repeated during sleep at $\sim 0100,0300$, and $0500 \mathrm{~h}$. All but one individual was able to sleep the entire night. This subject remained awake throughout the night, and his data are not included in further group analyses. Cerebral blood flow was determined by having subjects rest with their eyes closed in a small plastic hood with air flow maintained at $30 \mathrm{liter} / \mathrm{min}$. Air flow was continued throughout the night so as not to wake subjects by interrupting and restarting the flow. $9 \%$ nitrous oxide was introduced at the start of each blood flow measurement while blood was withdrawn continuously from the jugular venous and arterial vessels at $7 \mathrm{cc} / \mathrm{min}$ by a syringe pump (model 22; Harvard Apparatus, South Natick, MA). Samples of blood $(0.3 \mathrm{cc})$ for $\mathrm{N}_{2} \mathrm{O}$ content were collected simultaneously from the arterial and jugular venous cannulas at 30-s intervals for $6 \mathrm{~min}$ and then every $2 \mathrm{~min}$ until equilibrium was established at $20 \mathrm{~min}$. Arterial and jugular venous samples for oxygen saturation and glucose concentration were collected at the end of each blood flow determination. Glucose concentration was quantitated by glucose oxidase technique on a glucose analyzer (Beckman Instruments, Fullerton, CA ) with each sample determined 10 times to yield coefficients of variation of $0.5 \%$ in the range of glucose concentrations encountered. Oxygen saturation of hemoglobin was determined on an optical diffraction grating instrument (OSM3; Radiometer, Copenhagen, Denmark) with a coefficient of variation of $0.85 \%$.

An electroencephalograph instrument (model 6SS; Grass Instrument Co, Quincy, MA ) was used to monitor the eight channel continuous EEG recording. Sleep was staged according to Rechtschaffen and Kales (24). Arterial blood for insulin, growth hormone, glucagon, and systemic glucose kinetics was collected hourly. The venous nitrous oxide concentration reached equilibrium with the arterial compartment in all but one subject, and for that person was taken as evidence of contamination of venous return from extracerebral structures (25). The data for this individual were excluded from further analysis, leaving 10 subjects for data comparison.

Because rates of systemic glucose production and utilization were higher than expected basal values seen in other studies performed under normal postabsorptive conditions $(26,27)$, we postulated that a portion of the total systemic glucose production during the initial hours of sleep was caused by ongoing gut glucose absorption. Seven of the above subjects returned to be fed their final meal before sleep at $1200 \mathrm{~h}$. The meal was identical to the one they had previously consumed by $1730 \mathrm{~h}$. At $2000 \mathrm{~h}$, a primed continuous infusion of $6,6-\mathrm{D}_{2}$-glucose was begun to allow estimation of rates of systemic glucose turnover. Samples for glucose and glucose kinetics were collected every $60 \mathrm{~min}$ during the night while the subjects slept.

Analytical methods. Plasma insulin (28), C-peptide (28), glucagon (29), and growth hormone ( 30 ) were measured by radioimmunoassay. Samples for glucose turnover were prepared as previously described (31), and rates of glucose production and utilization were calculated from modified forms of Steel's nonsteady state formulas (31). Samples were analyzed for changes in trace amounts of $\mathrm{N}_{2} \mathrm{O}$ content with a $\mathrm{N}_{2} \mathrm{O}$ trace infrared spectrophotometer (Traverse Medical Monitors, Saline, MI) after the method of Robertson et al. (32).

Calculations and statistical methods. Cerebral blood flow (CBF) was calculated from the following form of the Fick equation (23):
$C B F=\frac{S V_{e q}}{\int_{0}^{e q}(A-V) d t}$,

where $V_{\text {eq }}$ is the relative concentration of $\mathrm{N}_{2} \mathrm{O}$ at equilibrium, and $S$ is the partition coefficient of nitrous oxide between blood and brain, known to be $1.0(23)$. The integrated area between the arterial and venous nitrous oxide curves, the denominator of the above equation, was calculated by simultaneous curve fitting of the arterial, and venous data sets to the class of sigmoidal curves were predicted by the equation:

$Y=\frac{A-D}{1+(X / b)^{\mathrm{c}}}+D$,

where $A$ is the minimum point of the curve, $b$ is the slope at the midpoint of the curve, $C$ is the middle point of the curve, and $D$ is the maximum point of the curve. Multiple iterations with forced convergence at equilibrium were performed with the SAS Procedure NLIN using a derivative-free option (33) to provide the coefficients that best described each set of curves. The derived coefficients were then used to generate data points every $0.1 \mathrm{~min}$, and sequential trapezoidal summation was used to calculate the final area between the curves. Brain glucose metabolism is the product of the arterial jugular venous glucose difference and the calculated cerebral blood flow. Brain oxygen metabolism was calculated similarly. Comparisons of interest were made with two-tailed paired Student's $t$ tests. Changes in glucose kinetics, glucose concentration, and hormone levels were made by repeated measures analysis of variance (33).

\section{Results}

Glucose concentration and rates of systemic glucose production and utilization (Fig. 1). Systemic glucose concentration appeared to decline slightly during the night, but this change failed to achieve significance. Rates of systemic glucose production and utilization declined in parallel until the final hours of the night and then plateaued at normal fasting rates (ANOVA, $P<0.002$ ).

Growth hormone, insulin, C-peptide, and glucagon levels (Fig. 2). Mean growth hormone values rose significantly during the night $(P<0.01)$. Individual growth hormone spikes were observed at differing times in each individual during sleep. The mean, peak growth hormone concentration was $591.6 \pm 97.1 \mathrm{pmol} /$ liter $(13.4 \pm 2.2 \mathrm{ng} / \mathrm{ml})$ during the night
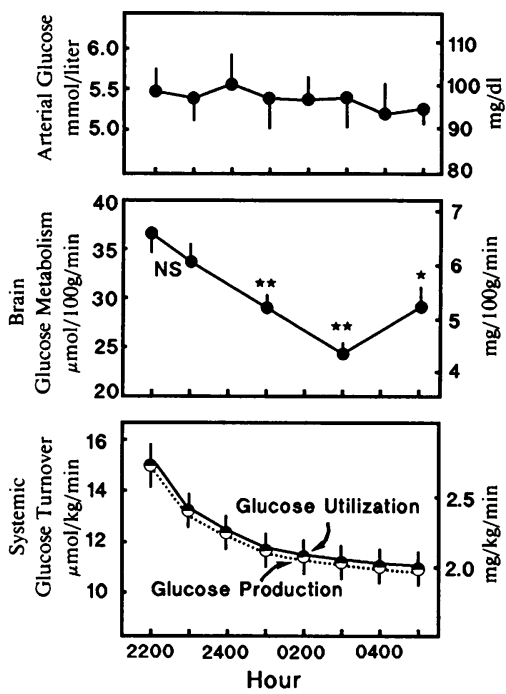

Figure 1. Mean \pm SE arterial glucose concentration (top panel) remained steady, while mean rate of brain glucose utilization (middle panel) was stable at the two presleep measurements and then fell progressively during the night $\left({ }^{*} P<0.01\right.$ and $\left.{ }^{* *} P<0.001\right)$. Systemic glucose production and utilization (bottom panel) fell significantly during the night ( $\mathrm{AN}$ OVA, $P<0.002$ ). 


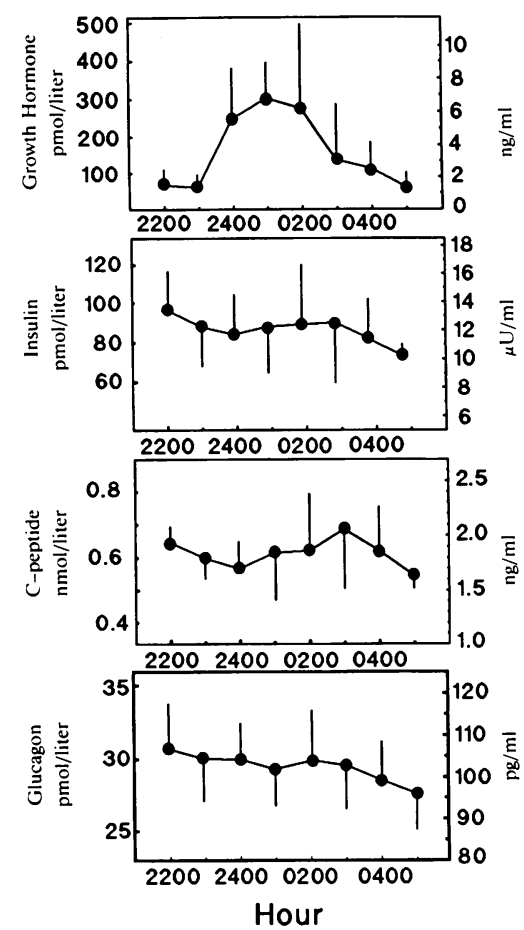

(data not shown). Insulin levels tended to decline slightly over the night. However, this trend was not statistically significant. C-peptide levels appeared to rise slightly at $0300 \mathrm{~h}$, but the overall concentration remained constant overnight. Glucagon appeared to fall slightly during sleep but this difference was, likewise, not significant.

Individual rates of brain glucose metabolism and stage of sleep (Fig. 3). All subjects had substantial decrements in rates of brain glucose metabolism during sleep. Values observed at $0100 \mathrm{~h}$ were intermediate between wakeful measurements and nadir values that were approached by $0300 \mathrm{~h}$. Only slight further decrements were observed during the remainder of the sleep period between 0300 and $0500 \mathrm{~h}$ in most subjects. Nadir

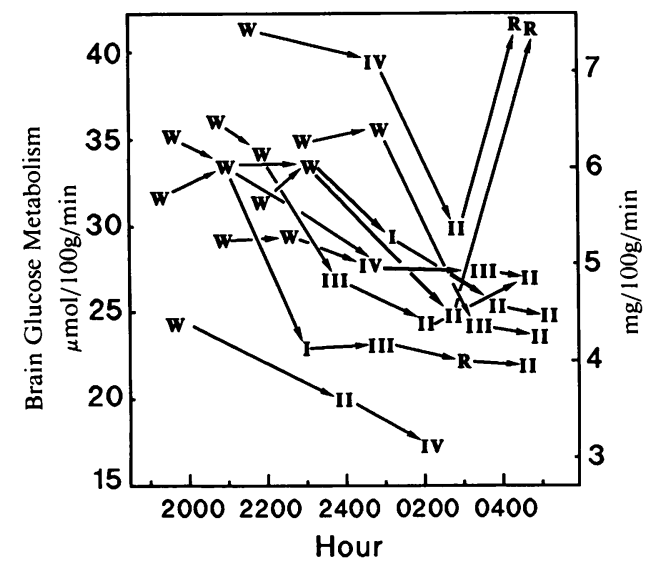

Figure 3. Individual rates of brain glucose metabolism before and during sleep correlated with level of sleep. Numerals and letters represent the stage of sleep. $W$, awake; $I$, dropout of $\alpha$ waves and appearance of $\theta$ waves; $I I, I I I$, and $I V$, increasing percent of time spent in delta wave (slow wave) sleep; $R$, rapid eye movement sleep. values were observed in stages II, III, and IV slow wave sleep. Thus, no relationship between stage of sleep and rate of brain glucose metabolism was apparent. Two out of the three subjects in whom REM sleep was observed demonstrated a pronounced rise in brain glucose metabolism to levels encountered before sleep.

Comparison of $2300 \mathrm{~h}$ (presleep) and $0300 \mathrm{~h}$ rates of brain metabolism (Table I). The mean rate brain glucose metabolism immediately before sleep $(2300 \mathrm{~h})$ and the mean rate at $0300 \mathrm{~h}$ are summarized in Table I. Overall, there was a $27 \%$ fall in brain glucose metabolism during sleep $(P=0.001)$. This decrement was the result of an overall $15 \%$ decrease in the arterial-venous glucose difference, $P=0.002$, and a $7.3 \%$ decrease in cerebral blood flow, $P=0.021$. The corresponding rates of brain oxygen metabolism fell by $12.0 \%, P=0.045$. The ratio of brain oxygen/glucose metabolism increased from $4.85 \pm 0.13$ to $5.33 \pm 0.22, P=0.05$. Related rates of systemic glucose production and utilization fell $19.1 \%, P=0.003$. Quantitatively, the change in the amount of glucose each subject's whole brain used, calculated by multiplying individual rates of brain glucose metabolism by the subject's brain weight (derived from nomograms of normal brain weight based on age and sex [(34]), fell from $390.1 \pm 27.2$ to $320.2 \pm 13.9 \mu \mathrm{mol} / \mathrm{min}$ $(P=0.005)$, while estimated whole body glucose utilization (individual systemic kinetic data multiplied by the subject's body weight) fell from $976 \pm 37$ to $874 \pm 20 \mu \mathrm{mol} / \mathrm{min}$ ( $P$ $=0.003$ ). Therefore, the fall in brain glucose metabolism is a significant contributor to the fall in whole body systemic glucose utilization.

Comparison of nocturnal rates of systemic glucose utilization occurring after varying time interval from final meal before sleep (Fig. 4). Rates of systemic glucose turnover fell significantly on both study nights $(2200$ vs $0400 \mathrm{~h}, P<0.002)$. At $\sim 10 \mathrm{~h}$ into the fast during each of the investigations (e.g., at $0400 \mathrm{~h}$, when the meal was served at $1730 \mathrm{~h}$ [closed bars], and at $2200 \mathrm{~h}$, when the meal was served at $1200 \mathrm{~h}$ [open bars]), there was no significant difference between rates of glucose production. Rate of glucose production at $2200 \mathrm{~h}$ (presleep) was significantly lower when the interval after the previous meal was prolonged $(P<0.001)$, thus supporting the concept that a portion, but not all, of systemic glucose production after a normally timed evening meal is most likely caused by ongoing food absorption (i.e., a combination of the endogenous glucose production and gut glucose absorption ).

Brain glucose metabolism and systemic glucose utilization in one subject unable to sleep throughout the night (Fig. 5). The one participant who was unable to sleep maintained the same rate of brain glucose metabolism (within 10\%) at all time points during the night. On the other hand, systemic glucose production and utilization decreased by $20 \%$ between 2300 and $0300 \mathrm{~h}$, just as it did in the other subjects who slept. The evening meal for this subject was served at $1700 \mathrm{~h}$. The shaded region represents $95 \%$ confidence intervals of systemic glucose utilization in sleeping subjects.

\section{Discussion}

We have demonstrated that cerebral blood flow, brain glucose, and oxygen metabolism all decrease during sleep in normal man. These reductions began early during sleep with most individuals, having initial decrements discernible by $0100 \mathrm{~h}$ and 


\begin{tabular}{|c|c|c|c|}
\hline & $2300 \mathrm{~h}$ value before sleep & $0300 \mathrm{~h}$ value during sleep & \\
\hline Brain glucose metabolism ( $\mu \mathrm{mol} / 100 \mathrm{~g}$ per min $)$ & $33.6 \pm 2.2$ & $24.3 \pm 1.1$ & $P=0.001$ \\
\hline (A-V) glucose difference (mmol/liter) & $0.643 \pm 0.024$ & $0.546 \pm 0.020$ & $P=0.001$ \\
\hline Cerebral blood flow (cc/100 g per min) & $50.3 \pm 2.8$ & $44.6 \pm 1.4$ & $P=0.021$ \\
\hline Brain oxygen metabolism $(\mu \mathrm{mol} / 100 \mathrm{~g}$ per min $)$ & $153.4 \pm 11.8$ & $128.4 \pm 8.4$ & $P=0.045$ \\
\hline Ratio of brain oxygen to glucose metabolism & $4.85 \pm 0.13$ & $5.33 \pm 0.22$ & $P=0.05$ \\
\hline Systemic glucose turnover ( $\mu \mathrm{mol} / \mathrm{kg}$ per min $)$ & $13.6 \pm 0.8$ & $11.0 \pm 0.5$ & $P=0.003$ \\
\hline Estimated whole brain glucose metabolism $(\mu \mathrm{mol} / \mathrm{min})$ & $390.1 \pm 27.2$ & $320.3 \pm 13.9$ & $P=0.005$ \\
\hline Estimated whole body glucose utilization $(\mu \mathrm{mol} / \mathrm{min})$ & $976 \pm 37.1$ & $874 \pm 20.5$ & $P=0.003$ \\
\hline
\end{tabular}

near maximal responses occurring by $0300 \mathrm{~h}$. Little additional decline occurred during the remainder of the night. Despite progressively greater periods of time spent in deeper slow wave sleep as the night progressed, there was no proportional reduction in brain glucose or oxygen metabolism. Therefore, once sleep is established, rates of brain glucose metabolism do not correlate with the central nervous system electrical activity (as judged by level of slow wave sleep), but instead seems to be more related to duration of sleep. In two of three subjects in whom REM sleep was observed for the majority of one of their cerebral blood flow measurements, there was an incremental rise in brain glucose metabolism. This later observation is consistent with the previous studies of Sakai (16), Maquet (20), and Buchsbaum (21), where increments in cerebral blood flow, glucose, and/or oxygen metabolism have previously been noted during REM sleep.

We indirectly assessed the contribution that continuing gut glucose absorption might make to the total systemic glucose production (gut plus other endogenous sources) by having the subjects consume their final meal before sleep at $1200 \mathrm{~h}$. By doing so, the period of fasting $(\sim 10 \mathrm{~h})$ before initial kinetic data were collected at $2200 \mathrm{~h}$ was comparable to other metabolic investigations conducted during the day with normal basal rates of systemic glucose production, $\sim 11 \mu \mathrm{mol} / \mathrm{kg}$ per min, being observed before sleep vs nearly $15 \mu \mathrm{mol} / \mathrm{kg}$ per min when the meal was provided at $1700 \mathrm{~h}$ (Fig. 4). Investigations conducted by Firth (35) and McMahon (36) using radioactively labeled meals of either simple carbohydrate or complex carbohydrate/mixed meals found that gut glucose absorption could be observed for 5-6 h after the meal. Likewise, we have demonstrated in studies of otherwise healthy patients with in-

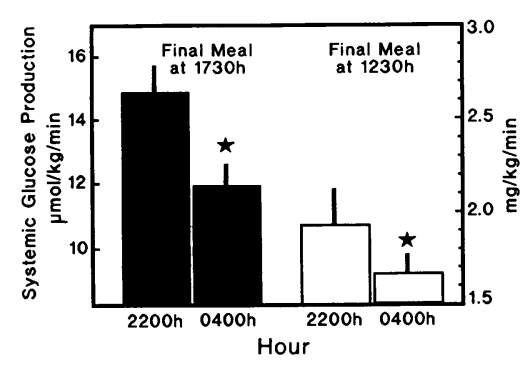

Figure 4. Comparison of nocturnal rates of systemic glucose metabolism. Closed bars, data when the final meal before sleep was consumed by $1730 \mathrm{~h}$; open bars, data when an identical final meal was consumed by $1230 \mathrm{~h}$. ${ }^{*} P<0.002$ relative to

$2200 \mathrm{~h}$ baseline for each night. Baseline values at $2200 \mathrm{~h}$ on each night were also different $(P<0.001)$. Also note that the closed bar at $0400 \mathrm{~h}$ and the open bar at $2200 \mathrm{~h}$ were not significantly different, and the duration of the fast at this point was equivalent, $10.5 \mathrm{~h}$. sulin-dependent diabetes mellitus that food absorption, assessed by labeling a mixed meal with glucose deuterated in the second position, occurs for 8-9 h (37). Based on these observations, we would suggest that most nocturnal metabolic studies that include isotopic glucose turnover are measuring, in part, ongoing gut glucose absorption from the evening meal during the early part of sleep. In our study, after a longer fast, and presumably in a true postabsorptive state, a significant decrement in systemic glucose production during sleep was still observed, consistent with the concept that brain glucose metabolism declines as the direct result of sleep, although we did not specifically assess this possibility.

Previous studies by Clore (4) noted that part, but not all, of the fall in systemic glucose production and utilization after a normally timed evening meal could be blocked by keeping subjects awake through the night. When combined with data from our single subject who remained throughout the night (Fig. 5) and who had no change in brain glucose metabolism (while having a preserved decline in systemic glucose utilization presumably caused by the final absorption of glucose from the gut), one might suggest that the combination of sleep deprivation and studying subjects in a true postabsorptive (not postprandial) state would obliterate the fall in systemic glucose turnover. This hypothesis has yet to be tested. However, if the sleeping group's mean fall in brain glucose metabolism is representative of the usual change that occurs during normal sleep, then the individual who remained awake all night would have experienced an additional $9.3 \mu \mathrm{mol} / 100 \mathrm{~g}$ per min (Fig. 1) had he slept. Multiplying this mean reduction by the nonsleeper's estimated brain weight (34), and dividing that product by his total body weight, an additional $1.58 \mu \mathrm{mol} / \mathrm{kg}$ per min fall in systemic glucose utilization could be expected by $0300 \mathrm{~h}$. Subtracting this further decrement from his original $0300 \mathrm{~h}$ data yields a rate of systemic utilization still well within the $95 \%$ confidence interval for the sleeping group ( shaded area, Fig. 5).

The central nervous system has been known to be directly involved in peripheral glucose metabolism since Claude Bernard pierced the floor of the fourth ventricle of rabbits and induced permanent diabetes (38). Biggers et al. demonstrated that by maintaining brain normoglycemia while allowing whole body hypoglycemia in dogs, the normal peripheral counterregulatory hormone responses (epinephrine, norepinephrine, cortisol, and pancreatic polypeptide) were substantially blunted (39). Thus, the brain appears to be indirectly involved in preserving and regulating systemic glucose production when threatened with inadequate glucose supplies. Although the current investigation demonstrates an interesting concordance 


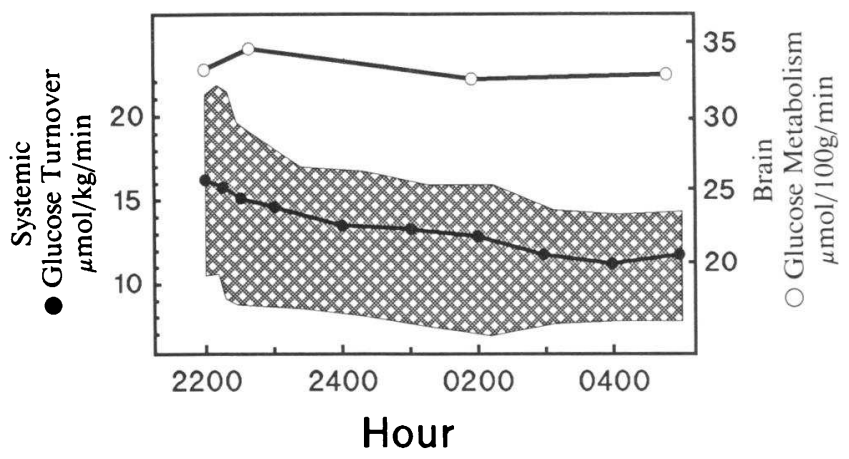

Figure 5. Data from an individual subject unable to sleep throughout the night (evening meal served at $1730 \mathrm{~h}$ ). The rate of systemic glucose production and utilization fell in parallel from 2200 and $0300 \mathrm{~h}$ and then plateaued. Rate of brain glucose metabolism remained constant throughout the night. For reference, the shaded area represents $95 \%$ confidence intervals for systemic glucose turnover data in subjects able to sleep.

between falling rates of brain glucose metabolism and systemic glucose utilization, it cannot delineate cause and effect. Levels of the key regulators of hepatic glucose production (insulin and glucagon ) did not change appreciably during the night, suggesting that decrements in production are unlikely to be the primary event explaining our findings. More likely, the fall in systemic utilization occurs as result of a normal decline in brain glucose metabolism, and hepatic production then follows, so that euglycemia is preserved. Alternatively, one might consider that a primary fall in hepatic production occurs, followed secondarily by a reduction in brain glucose utilization. Sleep is associated with reductions in glycerol and free fatty acid concentrations, which are known to reduce fructose 2,6bisphosphate levels $(40,41)$. Thus, decrements in these metabolic intermediates may indirectly lead to the fall in hepatic glucose production. How such a peripheral mechanism for decreased hepatic glucose output might lead to reduction in brain metabolism is not clear, since the systemic glucose concentration is not rate-limiting for brain metabolism until it falls below normal range (42). Subjects' glucose concentrations remained within the normal range during our studies; therefore, brain metabolism should not have been limited by supply and it seems unlikely that a decrement in hepatic glucose output is the primary metabolic event in this sequence of events. As a final, and more unlikely option, hepatic glucose output and brain metabolism may be regulated independently and the fact that euglycemia is maintained throughout the night is serendipitous.

Rates of glucose production have previously been observed to increase in the final hours of a night of sleep in normal subjects (4). Because of a concomitant increase in glucose utilization that occurred in those studies, there was no change in glucose concentration. In general, such increments occur during the hours of 0500 to $0800 \mathrm{~h}$ and are thought to be related to secretion of growth hormone during the first hours of sleep (43). In patients with insulin-dependent diabetes, this increased rate of hepatic glucose production generally results in a rise in plasma glucose concentration when coupled with stable insulin levels and is referred to as the "dawn phenomena" (44). During these investigations, we failed to observe any increase in glucose production and utilization during the final hours of observed sleep, most likely because of the fact that our final data was collected at $0500 \mathrm{~h}$, before the rise in glucose production normally begins. If one extrapolates this proposal to patients with insulin-dependent diabetes, where modest hyperinsulinemia occurs routinely during the night, then the stage should be set for nocturnal hypoglycemia. In the Diabetes Control and Complications Trial, a multicenter, randomized trial comparing near normalization of blood glucose levels to standard insulin therapy in $>1,400$ patients with insulin-dependent diabetes, the insulin replacement schemes used routinely produce stable or moderate hyperinsulinemia during sleep (45). Consistent with the above extrapolation, $>50 \%$ of the severe hypoglycemic events experienced by the patients in the Diabetes Control and Complications Trial have occurred temporally with our reported nocturnal nadirs in brain glucose utilization and systemic glucose production (46).

In the current study, the overall pattern of brain oxygen metabolism fell gradually over the night. The magnitude of the change was not nearly as great as that observed for glucose consumption but is in keeping with the overall reduction in systemic oxygen utilization reported by Brebbia (47). Only Mangold (13) and Madsen (17) have previously investigated nocturnal brain oxygen metabolism, and they came to disparate conclusions. Mangold's original observation of unchanged oxygen utilization has been questioned, since when one of the six participants he studied is excluded from analysis, there is a statistically significant decrease in oxygen metabolism. Madsen found a $25 \%$ reduction in brain oxygen metabolism during deep sleep and an increase during REM sleep in subjects studied on several different nights. In the present investigation, the quantity of oxygen required (on a molar basis) to metabolize glucose (at the nocturnal glucose metabolism nadir) was significantly greater than the oxygen/glucose ratio seen before sleep. Several possible metabolic events could explain this observation: $(a)$ oxidative glucose disposal could continue unchanged while there is a decrease in nonoxidative glucose disposal in brain tissue (i.e., less glycogen formation); $(b)$ an alternate fuel source such as ketone bodies may be oxidized to meet metabolic demands as glucose metabolism falls off; or $(c)$ there is a relative decrease in anaerobic metabolism. With respect to the first possibility, the brain is unable to synthesize or store more than a few minutes' worth of glucose for later use (48). Thus, a large enough decrease in glycogen synthesis to account for the $25 \%$ decrease in systemic glucose utilization we report seems unlikely, although no data exist on glycogen content before and after sleep. The second explanation also seems unlikely, since we failed to observe an increase in the arteriovenous ketone difference across the brain (data not shown). Other substrates (such as nonesterified fatty acids and amino acids) are not major energy substrates for brain metabolism (42) and were not assessed in this investigation. The final explanation is perhaps most reasonable. Fox et al. have demonstrated that during visual stimulation, brain glucose metabolism increases in the visual cortex, while oxygen utilization remains constant (49), implying that a relative increase in anaerobic metabolism occurs with increased neuronal activity. During sleep, cortical neuronal activity decreases (the opposite outcome of the Fox experiment) with median firing rates falling by $25 \%$ comparing wakefulness to slow wave sleep (1). In further support of an overall reduction in electrical activity, we and others (14-16) have observed a decline in cerebral blood flow, a parameter 
generally believed to be coupled to neuronal activity (50). Therefore, if sleep is viewed physiologically as a relative opposite of the wakeful state (e.g., less visual stimulation and reduced overall neuronal activity), and by the above reasoning results in a decrease in anaerobic glycolysis, then the oxygen/ glucose ratio would be expected to rise.

In summary, whether or not the primary metabolic event responsible for the fall in whole body glucose production and utilization is a fall in brain glucose metabolism during sleep remains unclear. However, several independent conclusions can be made: $(a)$ rates of brain glucose and oxygen metabolism decrease during the night (the former more than the later); $(b)$ quantitatively, the fall in brain glucose utilization accounts for a significant part of the decrement in measured peripheral glucose utilization; $(c)$ the fall in brain glucose metabolism occurs secondary to reduced cerebral blood flow and diminished brain glucose arteriovenous glucose difference; and $(d)$ these changes in brain energy and flow dynamics during sleep occur independent of stage of slow wave electrical activity (except during REM sleep where brain metabolism increases in most subjects) and instead appear to be more related to duration of sleep.

\section{Acknowledgments}

The expertise of Dr. Clifford Qualls in developing the curve fitting and integration programs is gratefully acknowledged. The care of the nursing staff on the General Clinical Research Center, especially Ms. Liz Candelaria, and the technical assistance of Ms. Rose Mills and Ms. Ellen Russo with the placement of the EEG leads and interpretation of the electroencephalograms is also gratefully acknowledged. The editorial assistance of Ms. Natalie Pacheco and Ms. Carolyn King are also acknowledged.

Dr. Boyle was a recipient of a Research and Development Award from the American Diabetes Association. This project was supported in part by dedicated Health Research Funds of the University of New Mexico and by a grant from General Clinical Research Program, National Center for Research Resources, NIH 5 M01 RR00997-15.

\section{References}

1. Hobsen, J. A., and R. W. McCarley. 1971. Cortical unit activity in sleep and waking. Electroencephalogr. Clin. Neurophysiol. 30:97-112.

2. Ravussin, E., S. Lillioja. T. E. Anderson, L. Christin, and C. Bogardus. 1986. Determinants of 24-hour energy expenditure in man. J. Clin. Invest. 78:1568-1578.

3. Miller. J. C., and S. M. Horvath. 1976. Cardiac output during human sleep. Aviat. Space Environ. Med. 47:1046-1051.

4. Clore, J. N., J. E. Nestler, and W. G. Blackard. 1989. Hepatic glucose output during sleep. Diabetes. 38:285-290.

5. Campbell, P. J., G. B. Bolli, P. E. Cryer, and J. E. Gerich. 1985. Pathogenesis of the dawn phenomenon in patients with insulin-dependent diabetes mellitus. N. Engl. J. Med. 312:1473-1479.

6. Tanaka, K., W. E. Nicholson, and D. N. Orth. 1978. Diurnal $\beta$ MSH(LPH) and ACTH in man. J. Clin. Endocrinol. \& Metab. 46:883-890.

7. Takahashi, Y., D. M. Kipnis, and W. H. Daughaday. 1968. Growth hormone secretion during sleep. J. Clin. Invest. 47:2079-2090.

8. Boyle, P. J., A. Avogaro, L. Smith, S. D. Shah, P. E. Cryer, and J. V. Santiago. 1991. Absence of the dawn phenomenon and abnormal lipolysis in type I (insulin-dependent) diabetic patients with chronic growth hormone deficiency. Diabetologia. 35:372-379.

9. Boyle, P. J., A. Avogaro, L. Smith, D. M. Bier, A. S. Pappu, D. R. Illingworth, and P. E. Cryer. 1992. Role of GH in regulating nocturnal rates of lipolysis and plasma mevalonate levels in normal and diabetic humans. Am. J. Physiol. 263 (Endocrinol. Metab. 26):E168-E172.

10. Ashmore, J., and D. Morgan. 1967. Metabolic effects of adrenal glucocorticoid hormones. In The Adrenal Cortex. A. B. Eisenstein, editor. Little, Brown and Company, Boston. pp. 249-267.

11. Franzini, C. 1992. Brain metabolism and blood flow during sleep. J. Sleep Res. 1:3-16.
12. Sawaya, R., and D. H. Ingvar. 1989. Cerebral blood flow and metabolism in sleep. Acta. Neurol. Scand. 80:481-491.

13. Mangold, R., L. Sokoloff, E. Conner, J. Kleinerman, P. G. Therman, and S. S. Kety. 1955. The effects of sleep and lack of sleep on the cerebral circulation and metabolism of normal young men. J. Clin. Invest. 34:1092-1100.

14. Madsen, P. L., S. Holm, S. Vorstrup, L. Friberg, N. A. Lassen, and G. Wilschiodz. 1991. Human regional cerebral blood flow during rapid-eye-movement sleep. J. Cereb. Blood Flow Metab. 11:502-507.

15. Townsend, R. E., P. N. Prinz, and W. D. Obrist. 1973. Human cerebral blood flow during sleep and waking. J. Appl. Physiol. 35:620-625.

16. Sakai, F., J. S. Meyer, I. Karacan, S. Derman, and M. Yamamoto. 1980. Normal human sleep: regional cerebral hemodynamics. Ann. Neurol. 7:471-478. 17. Madsen, P. L., J. F. Schmidt, G. Wildschiodtz, L. Friberg, S. Holm, S. Vorstrup, and N. A. Lassen. 1991. Cerebral $\mathrm{O}_{2}$ metabolism and cerebral blood flow in humans during deep and rapid-eye-movement sleep. Am. Physiol. Soc. 161:2597-2601.

18. Kennedy, C., J. C. Gillin, W. Mendelson, S. Suda, M. Miyaoka, M. Ito, R. K. Nakamura. F. I. Storch, K. Pettigrew, M. Mishkin, and L. Sokoloff. 1982. Local cerebral glucose utilization in non-rapid eye movement sleep. Nature (Lond.) 297:325-327.

19. Heiss, W. D., G. Pawlik, K. Herholz, R. Wagner, and K. Wienhard. 1985. Regional cerebral glucose metabolism in man during wakefulness, sleep, and dreaming. Brain Res. 327:362-366.

20. Maquet, P., D. Dive, E. Salmon, B. Sadzot, G. Franco, R. Poirrier, R. Von Frenckell, and G. Franck. 1990. Cerebral glucose utilization during sleep-wake cycle in man determined by positron emission tomography and $\left[{ }^{18} \mathrm{~F}\right]-2$-fluoro-2deoxy-D-glucose method. Brain Res. 513:136-143.

21. Buchsbaum. M. S., J. C. Gillin, J. Wu, E. Hazlett, N. Sicotte, R. M. Dupont, and W. E. Bunney, Jr. 1989. Regional cerebral glucose metabolic rate in human sleep assessed by positron emission tomography. Life Sci. 45:1349-1356.

22. Sherwin. R. S. 1980. Role of the liver in glucose homeostasis. Diabetes Care. 3:261-265.

23. Kety, S. S., and C. F. Schmidt. 1948. The nitrous oxide method for the quantitative determination of cerebral blood flow in man: theory, procedure and normal values. J. Clin. Invest. 27:476.

24. Rechtschaffen, A., and A. Kales. 1968. A Manual of Standardized Terminology. Techniques, and a Scoring System for Sleep Stages of Human Subjects. Brain Information Service/Brain Research Institute, UCLA, Los Angeles.

25. Lassen, N. A., and M. H. Lane. 1961. Validity of internal jugular blood for study of cerebral blood flow and metabolism. J. Appl. Physiol. 16:313-320.

26. Boyle. P. J., S. B. Liggett, S. D. Shah, and P. E. Cryer. 1988. Direct muscarinic cholinergic inhibition of hepatic glucose production in humans. $J$. Clin. Invest. 82:445-449.

27. Boyle, P. J., S. D. Shah, and P. E. Cryer. 1989. The prevention of hypoglycemia during fasting in humans: roles of insulin, glucagon and catecholamines. Ain. J. Physiol. 256 (Endocrinol. Metab. 19):E65I-E661.

28. Kuzuya, H., P. M. Blix, D. L. Horwitz, D. N. Steiner, and A. H. Rubenstein. 1977. Determination of free and total insulin C-peptide in insulin-treated diabetics. Diabetes. 26:22-29.

29. Ensinck, J. W. 1983. Immunoassays for glucagon. In Glucagon Handbook of Experimental Pharmacology. P. Lefebvre, editor. Springer-Verlag, New York. pp. 203-221.

30. Schalch. D. S., and M. L. Parker. 1964. A sensitive double antibody immunoassay for human growth hormone in plasma. Nature (Lond.). 203:11412.

31. Argoud, G., D. S. Schade, and R. P. Eaton. 1987. Underestimation of hepatic glucose production by radioactive and stable tracers. Am. J. Physiol. 193:E606-E615.

32. Robertson, C. S., R. K. Narayan, Z. L. Gokaslan, R. Pahwa, R. G. Grossman, P. Caram, Jr., and E. Allen. 1989. Cerebral arteriovenous oxygen difference as an estimate of cerebral blood flow in comatose patients. J. Neurosurg. 70:222230.

33. SAS Institute Inc. 1988. SAS/STAT ${ }^{\mathrm{TM}}$ Users Guide, Release 6.03 Edition. SAS Institute Inc. Cary, NC.

34. Sunderman, F. W., and F. Boerner. 1949. Normal Values in Clinical Medicine. W. B. Saunders Company, Philadelphia, pp. 664.

35. Firth, R. G., P. M. Bell, H. M. Marsh, I. Hansen, and R. A. Rizza. 1986. Postprandial hyperglycemia in patients with noninsulin dependent diabetes mellitus: role of hepatic extrahepatic tissues. J. Clin. Invest. 77:1525-1531.

36. McMahon, M., H. Marsh, and R. Rizza. 1989. Comparison of the patter of postprandial carbohydrate metabolism after ingestion of a glucose drink or a mixed meal. J. Clin. Endocrinol. \& Metab. 68:647-653.

37. Boyle, P. J., E. Comstock, A. O'Connor, R. J. Nagy, and D. S. Schade. 1992. Declining gut glucose absorption is the mechanism for onset of nocturnal hypoglycemia. Diabetes. 41:30A.

38. Bernard, C. 1957. An Introduction to the Study of Experimental Medicine. (1865.) (English translation by H. C. Green. 1927. Macmillan Journals Ltd., London.) Republished by Dover Publications, New York. p. 173.

39. Biggers, D. W., S. R. Myers, D. Neal, R. Stinson, N. B. Cooper, J. B. 
Jaspan, P. E. Williams, A. D. Cherrington, and R. T. Frizzell. 1989. Role of brain in counterregulation of insulin-induced hypoglycemia in dogs. Diabetes. 38:716.

40. Uyeda, K., E. Furuya, C. S. Richards, and M. Yokahama. 1984. Fructose2.6- $\mathrm{P}_{2}$, chemistry and biological function. Mol. Cell. Biochem. 48:97-120.

41. Hue. L., and M. H. Rider. 1984. Role of fructose 2,6-bisphosphate in the control of glycolysis in mammalian tissues. Biochem. J. 245:313-24.

42. Pardridge, W. H. 1983. Brain metabolism from the blood-brain barrier. Physiol. Rev. 63:1481-1535.

43. Campbell, P. J., G. B. Bolli, P. E. Cryer, and J. E. Gerich. 1985. Pathogenesis of the dawn phenomenon in patients with insulin-dependent diabetes mellitus: accelerated glucose production and impaired glucose utilization due to nocturnal surges in growth hormone secretion. N. Engl. J. Med. 312:1473.

44. Boyle. P. J., A. Avogaro, L. Smith, S. D., P. E. Cryer, and J. V. Santiago.

1992. Absence of the dawn phenomenon and abnormal lipolysis in type 1 (insu- lin-dependent ) diabetic patients with chronic growth hormone deficiency. Diabetologia. 35:373-379.

45. Schade. D. S., J. B. Santiago. J. S. Skyler, and R. A. Rizza. 1983. Intensive Insulin Therapy. Excerpta Medica, Inc., Princeton, NJ. pp. 129-148.

46. The DCCT Research Group. 1991. Epidemiology of severe hypoglycemia in the DCCT. Am. J. Med. 90:450-459.

47. Brebbia, D. R., and K. Z. Altshuler. 1965. Oxygen consumption rate and electroencephalographic stage of sleev. Science (Wash. DC). 150:1621-1623.

48. Siesjo, B. K. 1978. Utilization of substrates of brain tissues. In Brain Energy Metabolism. Wiley, NY. pp. 1-20.

49. Fox, P. T., M. E. Raichle, M. A. Mintun, and C. Dence. 1988. Nonoxidative glucose consumption during focal physiologic neural activity. Science (Wash. DC). 2:462-464.

50. Lou. H. C.. L. Edvinsson, and E. T. MacKenzie. 1987. The concept of coupling blood flow to brain function: revision required? Ann. Neurol. 22:289297. 